\title{
Del amor a lo siniestro en Blade Runner 2049
}

\author{
Marcos Joaquin Ferrer|marferre@uji.es \\ Universitat Jaume I
}

\section{Palabras clave}

"Siniestro", "representación”, "capitalismo",

"muerte", "amor", "replicante"

Sumario

1.Consideraciones previas

2. Más humanos que los humanos. Joi y ' $\mathrm{K}$ '

3. De entre los muertos (I). Deckard y Rachel.

(2h $08^{\prime} 55^{\prime \prime}-2 \mathrm{~h} 16^{\prime} 56^{\prime \prime}$ )

3.1. De entre los muertos (II). El regreso de Joi

(2h 16'56''-2h 18'39' )

4. Conclusiones: lo siniestro en Blade Runner 2049

5. Bibliografía

\section{Resumen}

El presente artículo aborda lo siniestro en Blade Runner 2049 (Villeneuve, 2017), puesta en relación con Blade Runner (Scott, 1982), a partir de la presencia en la película de los elementos y temas que, según Freud, son portadores del fenómeno. El objetivo de este artículo es comprobar si la mera presencia de estos (la incertidumbre, el animismo, la amputación de los ojos, el doble y la repetición) basta para que lo siniestro irrumpa, o si es necesario que su carga alcance a la materialidad fílmica, rasgando los códigos del modo de representación hegemónica, para que el fenómeno alcance toda la radicalidad de su manifestación con la aparición de la angustia

que le caracteriza. Para ello analizaremos diversas secuencias que establecen la relación entre Joi y ' $\mathrm{K}$ ' y Deckard y Rachel, porque es en ellas donde lo siniestro toma forma a partir del amor y de la figura de la mujer que retorna de la muerte. Pondremos el foco igualmente en la relación que se establece entre lo siniestro y aquello que surge entre la resistencia del sujeto y las imágenes de consumo capitalistas.

\section{Cómo citar este texto:}

Marcos Joaquin Ferrer (2021): Del amor a lo siniestro en Blade Runner 2049, en Miguel Hernández Communication Journal, Vol. 12 (1), pp. 181 a 202. Universidad Miguel Hernández, UMH (Elche-Alicante). DOI: https://doi.org/10.21134/mhcj.v12i.944 


\section{From love to the sinister in Blade Runner 2049.}

Marcos Joaquin Ferrer|marferre@uji.es

Universitat Jaume I

Keywords

"Uncanny", "representation", "capitalism", "death",

"love", "replicant"

Summary

1.Previous considerations

2. More humans tan humans. Joy and ' $\mathrm{K}$ '

3. From the dead (I). Deckard and Rachel (2h 08

$55^{\prime \prime}-2 \mathrm{~h} 16^{\prime} 56^{\prime \prime}$ )

3.1. From the dead (II). Joi's return (2h 16 $56^{\prime} 6^{\prime \prime}$ 2h $18^{\prime} 39^{\prime \prime}$ )

4. Conclusions: the uncanny in Blade Runner 2049

5. Bibliography

\section{Abstract}

This article addresses the sinister in Blade Runner 2049 (Villeneuve, 2017), related to Blade Runner (Scott, 1982), starting with the elements and themes that, according to Freud, were the carriers of the phenomenon. The objective of this article is to check if the mere presence of these (the uncertainty, the animism, the eyes amputation, the doppelganger, and the repetition) in the film is enough for the sinister to erupt. Another way of checking the sinister's presence is by looking at the filmic materiality tearing the codes of the hegemonic mode of representation. This

way the phenomenon would reach all the radicality of its manifestation with the apparition of the anguish. In order to do this, we will base ourselves on various sequences that establish the relationship between Joi and ' $\mathrm{K}$ ' and the one between Deckard and Rachel. It is in these relationships where the sinister takes shape from love and death in the figure of the woman who returns from death. We will also focus on the connection that is established between the sinister and the result of combining the resistance of the subject with the images of capitalist consumption.

\section{How to cite this text:}

Marcos Joaquin Ferrer (2021): Del amor a lo siniestro en Blade Runner 2049, en Miguel Hernández Communication Journal, Vol. 12 (1), pp. 181 a 202. Universidad Miguel Hernández, UMH (Elche-Alicante). DOI: https://doi.org/10.21134/mhcj.v12i.944 


\section{Consideraciones previas}

El presente artículo aborda lo siniestro en Blade Runner 2049 (Villeneuve, 2017) a partir principalmente de dos secuencias en las que retornan de entre los muertos las imágenes del amor perdido (Rachel y Joi) y que entrelazan la secuela de Villeneuve con su predecesora Blade Runner (Scott, 1982). Analizaremos cómo lo siniestro supura en el choque de esos retornos, porque esas relaciones de amor están mediadas por la presencia de la muerte.

Con el fin de aproximarnos a estas cuestiones aplicaremos la metodología del análisis fílmico. La definición de lo siniestro de Freud en su artículo Lo siniestro (Das unbeimliche) (1992b), nos servirá de referente para apreciar su irrupción en Blade Runner 2049. Lo siniestro para Freud es "... aquella variedad de lo terrorífico que se remonta a lo consabido de antiguo, a lo familiar desde hace largo tiempo" (Freud, 1992b: 220). El mismo autor advierte que el fenómeno es escurridizo, extraordinario e incluso ambivalente. De ahí que el término alemán unheimlich sea el que, según él, mejor se le aproxime ya que la palabra de la que deriva (heimlich) condensa dos conceptos ajenos: lo familiar y lo oculto. Así, unheimlich es "todo lo que estando destinado a permanecer en secreto, en lo oculto, ha salido a la luz" (Freud, 1992: 225).

Para Freud lo siniestro está relacionado y se confunde con la angustia y lo terrorífico, por ello trata de hallar aquello que dentro de la angustia es específicamente siniestro: "Uno querría conocer ese núcleo, que acaso permita diferenciar algo «ominoso» dentro de lo angustioso" (Freud, 1992b: 219).

El objetivo final de este proyecto es comprobar si en Blade Runner 2049 lo siniestro surge a partir de los temas portadores de la carga del fenómeno: la incertidumbre, el animismo, la amputación de los ojos, el doble y la repetición (Freud, 1992b); o si por el contrario estos necesitan que uno de ellos, la incertidumbre, se traslade a la forma fílmica suspendiendo o quebrando los códigos de representación del M.R.I. ${ }^{1}$ para que lo siniestro emerja en toda su radicalidad.

De entre los temas portadores de lo siniestro en Freud nos interesa especialmente la incertidumbre acerca del estatuto de la realidad en el relato, porque atraviesa al resto de manifestaciones que parecen depender de ella. Freud se refiere a la estética literaria y pone múltiples ejemplos de narraciones en los que la presencia de los temas siniestros no supone la emergencia del fenómeno. "En tal caso todo lo ominoso que había adherido a esas figuras se disipa, en tanto constituyen las premisas de esa realidad poética (...) Adecuamos

${ }^{1}$ Seguimos la definición de M.R.I. (Modo de Representación Institucional) y cine hegemónico esgrimida por Gómez Tarín: “...entendemos por M.R.I. el modo hegemónico en cada momento, coincidente en su día con el 'clásico' pero transformado con el paso del tiempo. Esta puntualización es importante porque ese vigor (...) es el mismo que permite al modelo institucional asumir cambios, e incluso rupturas, integrando en su proyecto codificador elementos que, en principio parecen radicalmente opuestos" (Gómez Tarín, 2006: 20). El mismo autor cita las Teorías del cine de Robert Stam (2001) para establecer una serie de características de este cine hegemónico, que son: transitividad narrativa, identificación, transparencia, diegésis única, clausura, placer y ficción. La prioridad del M.R.I. es ocultar al ente enunciador y ofrecer certidumbre interpretativa, a lo que contribuye de manera fundamental la plena interiorización por el espectador de los códigos del M.R.I. 


\section{MHCJ Vol. 12 (1) | Año 2021 - Artículo no 9 (176) - Páginas 181 a 202 - mhjournal.org}

nuestro juicio a las condiciones de esa realidad forjada por el autor" (Freud, 1992b: 249).

La narración debe entonces generar incertidumbre, mantener la duda interpretativa acerca del carácter real o no de esas impresiones para que lo siniestro haga acto de presencia. El relato de E.T.A Hoffmann El hombre de Arena (2016), le sirve a Freud de paradigma de lo siniestro literario-estético no solo porque en él aparecen los temas siniestros sino, fundamentalmente, porque lo siniestro se gesta en el tratamiento que hace Hoffmann de las convenciones narrativas con el fin de hacernos dudar del estatuto de la realidad. Así pues, la aparición de los motivos siniestros no garantiza por su mera presencia la irrupción de la sensación.

Hoffmann utiliza una serie de técnicas literarias (carácter epistolar, múltiples narradores con distintos saberes pero ninguno omnisciente...) con el objetivo de generar incertidumbre en el lector en la interpretación de lo narrado, así abre el relato al sentido y lo implica activamente. El escritor sabe que las convenciones narrativas guían al espectador en la interpretación del sentido del relato hasta conducirle a una clausura narrativa. Por este motivo cuestiona las convenciones para hacer zozobrar la certidumbre, lo siniestro brota entonces de las fisuras narrativas, entre los huecos de información que el relato no cubre.

No hay una clara relación causa-efecto en El Hombre de Arena, no hay cierre que encaje las piezas y nos dé un sentido unívoco en la interpretación de la obra, al contrario, este permanece abierto, será el lector el que debe hacerse cargo de él. De entre todos los temas siniestros de Freud, la incertidumbre ocupa a nuestro entender un lugar privilegiado. Está ligada al tratamiento, es la forma que carga de potencia siniestra al resto de temas que alberga el relato.

Certidumbres y convenciones están pues estrechamente relacionadas. En el caso del cine, los códigos del M.R.I. plenamente asumidos por parte del espectador son producto de la hegemonía de un tipo de representación que excluye otros modelos. Partimos de la hipótesis de que para que lo siniestro emerja en toda su radicalidad, la película debe suspender o quebrar las convenciones de los asumidos códigos del M.R.I. con el fin de generar incertidumbre ${ }^{2}$. Se abre así el sentido interpretativo de la obra que apela al espectador como parte activa de la construcción de sentido.

${ }^{2}$ El M.R.I. "Centra la imagen, provoca la identificación de la mirada del espectador con la cámara, al tiempo que "penetra" la escena y asume puntos de vista correspondientes a personajes y clausura narrativamente el relato" (Burch, 1985: 184-185). Precisamente una de las reglas sagradas del M.R.I. es la prohibición de mirar directamente a cámara por parte del actor (siempre y cuando esta mirada no esté integrada y justificada en la diégesis). Este gesto desvelaría el mecanismo cinematográfico, rompería la identificación de la mirada del espectador con la cámara que señala Noël Burch. Pues bien, esta mirada a cámara es un ejemplo de cómo a partir de la incertidumbre que genera en el espectador la suspensión de las convenciones del M.R.I. puede irrumpir lo siniestro. Como comenta Gómez Tarín (2007: 10) a colación de las miradas a cámara que tienen lugar en The Curse of the Cat People (Wise, Fritsch, 1944): "La detención de la mirada [...] en la cámara - abiertamente el espectador - tiene [...] un efecto de extrañamiento como objetivo, pero además anula la clausura del film e inscribe la indeterminación. ¿Qué debemos entender como realidad o como ficción? El discurso se abre y ambos caminos son perfectamente legibles. [...] finalmente lo siniestro es una presencia que habrá que aceptar en toda situación porque puede emerger en cualquier momento y lugar (tiempo y espacio). Cine y realidad (como constructo) se entrecruzan". 


\section{Más humanos que los humanos. Joi y ' $K$ '.}

Antes de pasar a analizar las secuencias que establecen la relación con lo siniestro a partir del retorno de la muerte de las imágenes de Rachel y Joi, es oportuno destacar el eje temático amoroso que desde el arranque se establece entre las parejas Joi - ' $\mathrm{K}$ ' y Rachel -Deckard. Ambas tienen un nexo común; el amor y la pérdida. En ese futuro distópico que nos presenta Blade Runner 2049 el amor pretende convertirse en algo disponible al goce del consumidor. Las imágenes de Rachel y Joi retornarán de la muerte en forma de réplicas.

En este sentido es destacable que ya en la presentación de Joi, esta muestre su condición de producto destinado al consumidor que demanda amor en estado líquido. Quizás porque el capitalismo en ese futuro inquietantemente próximo ha soslayado ya cualquier otra posibilidad afectiva. El desvelamiento de Joi como objeto de consumo se produce precisamente al quedar suspendida bajo la lluvia mientras está plenamente entregada al goce amoroso con ' $\mathrm{K}^{\prime}\left(23^{\prime} 14^{\prime}\right.$ ') (fig. 1).

Fig. 1. Fotograma de Blade Runner 2049 (Villeneuve, 2017). Blu-ray. Warner Bros. Entertainment Inc. (C)

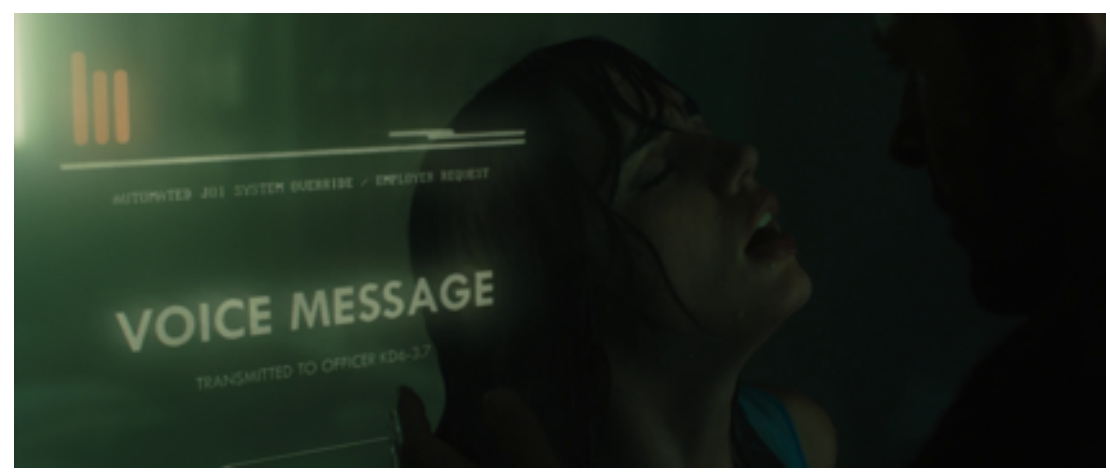

Joi nos fue presentada momentos antes, cuando después de una dura jornada de trabajo ' $\mathrm{K}$ ' llega a su casa situada en un edificio degradado y con un ambiente tan hostil como el clima. Al llegar al hogar le recibe Joi, y lo hace a partir de la puesta en marcha de un programa que ' $K^{\prime}$ activa (16'35'). Primero nos llega su voz acompañada de un clásico y acogedor hilo musical. Esa voz acusmática, sin cuerpo presente, que es todavía Joi lo recibe con familiaridad e interactúa con él desde la aparente complicidad de una rutina establecida entre ambos.

Joi es el simulacro de una compañera en la que asentar el sentimiento de pertenencia a algo, un hogar, una evasión y refugio de una realidad implacable. Esta se hace finalmente visible como un sofisticado holograma translúcido de muy leve o dudosa materialidad que surge de un proyector cenital de recorrido limitado. Joi aparece bella y radiante, vestida como una perfecta ama de casa mientras suena un tema de los años sesenta. Pero esa familiaridad está fuera de lugar en el sórdido mundo individualista que habita ' $\mathrm{K}$ '. Es representación, algo hecho a imagen o semejanza de otra cosa. En este caso Joi es un sustituto de las necesidades 
afectivas básicas que son recicladas y ofertadas para su consumo por Wallace.

' $\mathrm{K}$ ', que se ha cocinado algo rápido y poco sugerente, espera a que Joi le sirva la imagen de un apetitoso plato de comida, tan inmaterial como ella, que sobrepone a su cena en una perfecta metáfora de la realidad del mundo en el que se desenvuelve. Simulacro sobre simulacro. En primer lugar estamos asistiendo a la relación que mantiene ' $K$ ', un replicante, con Joi, un sofisticado programa virtual de Wallace, la misma compañía que creó a ' $\mathrm{K}$ '. Las dudas nos asaltan ya acerca de la posibilidad real de esa intimidad, ¿pueden acaso sentir? ' $K$ ' es consciente de que Joi es un programa, participa del juego que esta le propone con afán precisamente de quedarse en su decorado para hacerla real a través del deseo.

Esta secuencia expone uno de los principales ejes temáticos de la película, la adaptabilidad del capitalismo líquido que se nutre de lo afectivo, de lo más íntimo e intangible. Algo que ya podemos apreciar hoy perfectamente en nuestra realidad tecnológica, solo queda elidir al sujeto que hay detrás de los perfiles de las páginas de contactos y quedarnos con la imagen idealizada de ellos mismos que exponen los usuarios. Moldear esa imagen que se ofrece a gusto del consumidor es lo que asegura el eslogan publicitario de Joi: "es todo lo que quieres (ver, oir)".

Joi es una experiencia sentimental para el pleno goce individual que ya no tiene que soportar la incomodidad de hacerse cargo de la presencia y la complejidad de otro sujeto, recordemos que ' $\mathrm{K}$ ' activa (resucita) a Joi al llegar a casa. El capitalismo en su forma más radical, solo el individuo consumiendo su propio deseo especular, ningún espacio para lo común que no sea el campo vacío ocupado por la ideología. Pero ¿es esto posible o es la próxima contradicción del nuevo capitalismo líquido?3 ${ }^{3}$.

Lo interesante de esta secuencia que presenta a Joi es precisamente cómo introduce esta adaptación del capitalismo a través de su ausencia de carnalidad, el objeto de consumo perfecto no es el objeto en sí, sino el exceso inasible de su goce. Así, Joi es la ideología misma seduciéndonos ya en el ámbito más íntimo, en lo afectivo, para nutrirse de él. Joi no es una mujer, sino solo su imagen fantaseada a partir de la época costumbrista del sueño americano (fig. 2), iconografiado, entre otros, por Norman Rockwell.

La presencia de Joi potencia lo familiar como referente, que ahora funciona como objeto melancólico, como ideal que nunca existió. Esa imagen ha rellenado su propio vacío y devenido real como idealización, como deseo. La imagen que ha comprado ' $\mathrm{K}$ ' a su propia compañía es la de una mujer que no lo es, que condensa en su materialidad fantasmática aquello que Lacan afirmó una vez: la mujer no existe, es un invento del hombre ${ }^{4}$.

${ }^{3}$ En el sentido evanescente que le otorga al término Zygmunt Bauman en sus obras Modernidad líquida (2000), Amor líquido (2005) y Vida líquida (2013). En las que expone nuevas formas de sometimiento del capitalismo a partir del fomento de una inseguridad constante en todas las facetas de la vida, de las que este a su vez se retroalimenta.

${ }^{4} \mathrm{El}$ carácter sublime de un objeto no es propio de su naturaleza intrínseca, sino solo un efecto del lugar que ocupa (o no ocupa) en el espacio fantasmático [...] la elevación de una mujer terrenal a la condición de objeto sublime siempre entraña un peligro para la desdichada criatura encargada de encarnar la Cosa, puesto que "la mujer no existe" (Žižek, 1994: 142). 
¿Existe una propuesta más sugerente que la de Joi para mostrarnos cómo el capitalismo en el que nos desenvolvemos es capaz de negociar y generar necesidades de sus propias contradicciones? ' $\mathrm{K}$ ', creado por la corporación Wallace para ser esclavo-productivo en la policía de Los Ángeles, compra a su vez un producto de la misma Wallace para suplir las necesidades que ella misma le negó al crearlo. El replicante perfecto es aquel que supera en rendimiento productivo a los humanos, pero es a la vez totalmente sumiso para rebelarse contra la explotación, al contrario de lo que sí hicieron sus imperfectos predecesores, los Nexus 6 en Blade Runner.

Fig. 2. Fotograma de Blade Runner 2049 (Villeneuve, 2017). Blu-ray. Warner Bros. Entertainment Inc. C)

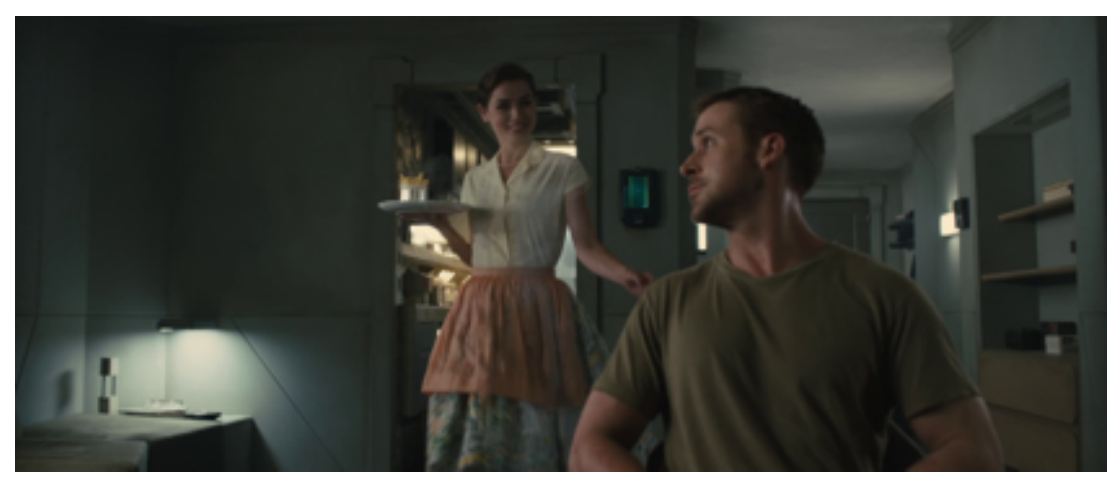

Lo familiar del recibimiento de Joi a ' $\mathrm{K}$ ' comienza pues a generar extrañeza por su exceso, por el cliché que hace evidente el vacío de esa imagen costumbrista del sueño estadounidense. Una representación en la que ' $\mathrm{K}$ ' encarna al hombre que llega del trabajo al núcleo familiar, mientras Joi es la mujer que espera en casa. Se trata, de nuevo, de un simulacro sobre simulacro representado por dos replicantes, dos variantes de autómatas que en su emulación de lo humano desean lo que desea ese otro 'humano' que anhelan ser. Ambos recurren a esas imágenes y roles en los que supuestamente habita la felicidad de sus referentes humanos y con las que la ideología encubre la alienación de su modo de vida.

Un solo plano condensa perfectamente esa idea de encubrimiento ideológico de la realidad capitalista, el del holograma de la apetitosa cena de Joi sobreponiéndose al plato que ' $K$ ' se ha preparado (fig. 3). Aquí la imagen del deseo cubre literalmente, con el beneplácito de ' $\mathrm{K}$ ', la desagradable cena que este debe comerse. Esto es, consciente de la realidad antepone voluntariamente la ilusión.

Se trata de un mecanismo opuesto al que Žižek señala en Guía ideológica para pervertidos (The Pervert's Guide to Ideology) (Fiennes, 2012) y que acontece en la película Están vivos (They Live) (Carpenter, 1988). En ella el protagonista, John Nada, encuentra unas gafas que le permiten ver a través de los ítems que le asedian en su cotidianeidad para descubrir la verdadera razón de ser de la publicidad, el dinero y los medios de comunicación de masas. Tras ellos encuentra mensajes destinados a la obediencia y esclavitud productiva de los humanos. Es decir, el protagonista ve lo que los fetiches capitalistas ocultan acerca de su ideología. 
Fig. 3. Fotograma de Blade Runner 2049 (Villeneuve, 2017). Blu-ray. Warner Bros. Entertainment Inc. (C)

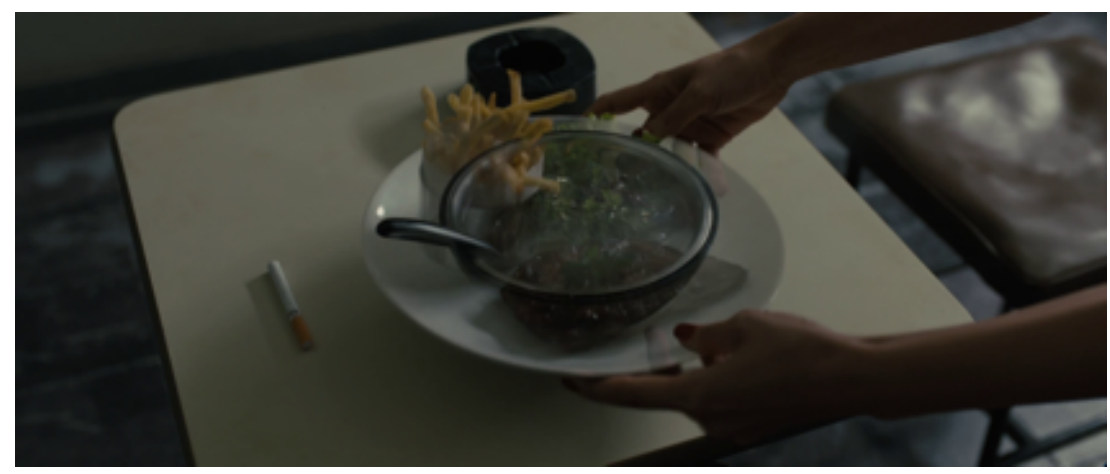

' $\mathrm{K}$ ', por el contrario, en su actitud ante la cena proyecta la actual sociedad del fin de la historia $^{5}$; esta propone un futuro que es solo tiempo por llegar, presente continuo de nuestra actualidad sin horizonte ni alternativa de cambio, donde el otro, lo colectivo, ya no existe. Es por ello que allá donde John Nada se rebela contra la realidad que ocultan las imágenes, ' $\mathrm{K}$ ' elige quedarse en ellas, prefiere habitar su fantasía, en el mudable goce que le ofrece la etérea Joi.

Sin embargo, sobre la naturaleza de Joi también planea la sombra de la duda acerca de su consciencia, de que sea más humana que los humanos, una replicante que prescinde de la carcasa del cuerpo y es utilizada como imagen-deseo moldeable a la fantasía.

Inquietante duda que nos azota todavía más cuando en un bello gesto de amor, o de perfección del programa, Joi acuerda la cita con Mariette, la replicante prostituta, para tomar posesión de su cuerpo, cubrirlo con su imagen como hizo con el plato de cena de ' $\mathrm{K}$ ' y materializarse así ante él para tener relaciones sexuales. "Ella es real”, "quiero ser real para ti", le dice Joi. Curioso trío con médium incluida (Mariette) en la que su cuerpo es poseído por la imagen del deseo de ' $K$ '. Una sincronización imperfecta y bellísima en la que las imágenes de ambas mujeres oscilan sobre un solo cuerpo (fig. 4); por un lado la mujer idealizada, ese fantasma que es Joi, por otro, la prostituta real, la carnal Mariette ${ }^{6}$.

Secuencia que constituye un perfecto ejemplo de la mujer como fantasma ${ }^{7}$, como idealización del hombre y que nos remite a Vértigo (Hitchcock, 1958) a la anhelada Madeleine, mero personaje, ficción, otro fantasma tomando posesión de la imperfecta y real Judy en otro acto de amor de esta última. En ambos casos es la fantasía, el sueño imposible, el que se antepone a la realidad.

${ }^{5}$ Concepto de Francis Fukuyama en El fin de la historia y el último hombre. (1992).

${ }^{6}$ Lo humano queda aquí elidido, se constituye en el referente aspiracional de este trío mediante su entrega al acto amoroso.

7 "El fantasma conecta al que habla con lo real que ha perdido" (Alemán y Larriera, 1998: 254). 
Fig. 4. Fotograma de Blade Runner 2049 (Villeneuve, 2017). Blu-ray. Warner Bros. Entertainment Inc. (C)

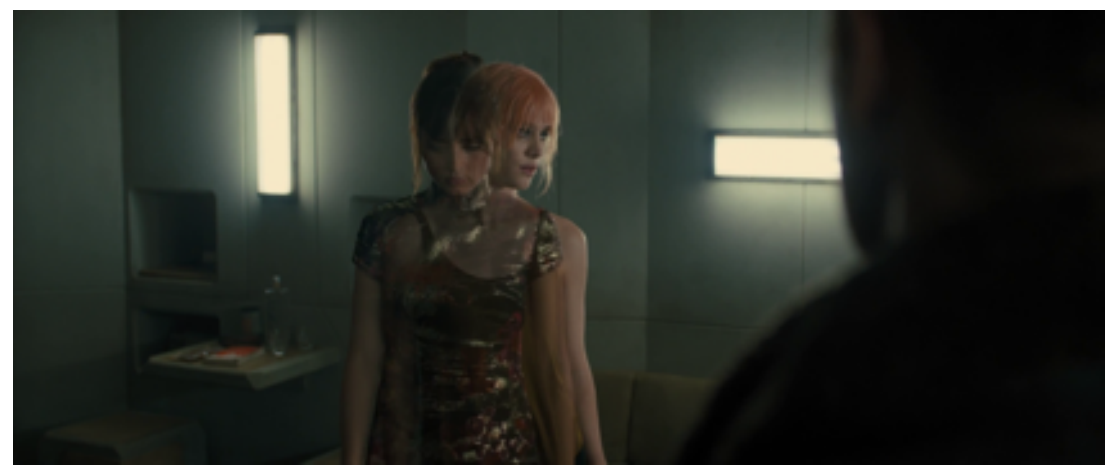

De ahí que Joi al acabar el acto sexual le invite a la prostituta a marcharse: "He acabado contigo" le dice, en una sintomática inversión de las posiciones, porque aquí es el fantasma de la mujer la que trata a la real como objeto agotado, ya inservible. Su cuerpo es prescindible, es más, debe serlo para que el fantasma y el deseo sigan su ciclo sin fin.

En esa rivalidad entre la mujer y su fantasma, entre la ideal y la real, que se fragua para comercializar con su deseo, Mariette le responde a Joi con una verdad demoledora acerca de su naturaleza que es extrapolable a la del propio capitalismo: "Silencio. He estado dentro de ti, no hay tanto ahí como crees". Mariette sabe que la consistencia de Joi se basa en una mentira, justo la que ofrece su imagen perfecta que solo puede ser rellenada por el deseo del otro. Joi en sí misma no es nada, solo puro vacío.

Quizás por ello y acto seguido a la posesión de ese cuerpo, Joi añade otro acto de amor por 'K'; le pide ser borrada de la consola y que rompa la antena por medio de la cual pueden localizarle. Queda así recluida en un diminuto soporte físico, en el emanador portátil que ' $\mathrm{K}$ ' lleva consigo. Esto es lo más parecido a un cuerpo que puede poseer, pues si este se daña, como sucederá, ella desaparece, "como una mujer real". El anhelo de un cuerpo como el que poseen los seres reales, es también pulsión de muerte que ligada al amor le lleva a reducirse a la fisicidad de ese aparato que ahora la contiene. La desaparición, ese sacrificio por proteger a ' $\mathrm{K}$ ', es lo más parecido a la experiencia de amor y muerte para Joi y es el gesto que reivindica su individualidad, su consciencia, su yo existo ante el otro (' $\mathrm{K}$ ') que me reconoce como igual.

Mediante el emanador Joi se convierte en la omnipresente y fantasmal compañera de ' $\mathrm{K}$ ' allá donde esté. En esa recién adquirida "libertad", el primer deseo de Joi es sentir la lluvia y ambos ascienden a la azotea del edificio. Es esta una secuencia tratada con los códigos propios del género romántico en ritmo y juego de planos-contraplanos que reflejan las emociones compartidas de ambos personajes, con leitmotiv extradiegético incluido que subraya el momento previo al beso.

De hecho, el tratamiento romántico es tan evidente en esta secuencia que cuando Joi le dice: "soy muy feliz cuando estoy contigo", 'K' le pide, o casi le exige, que no diga eso. El exceso 
de cliché romántico que tiene enfrente le evidencia lo fantasmático del acto, le desvela el programa diseñado para su satisfacción que es Joi. El problema es que ' $\mathrm{K}$ ' necesita creer en ella para soslayar su soledad y olvidar que es él mismo, su deseo, el que la sostiene.

Aquí lo siniestro se filtra no solo en la repentina suspensión de Joi, reconvirtiéndola en autómata, sino también en la súbita ruptura del tratamiento romántico, de sus códigos institucionales que guían la interpretación de la secuencia. Apunta a algo más ese deslizamiento de lo siniestro, la detención de Joi escenifica el señuelo de la imagen, su fantasía para el sometimiento y control, a la vez que el angustioso vacío que oculta, un vacío que es el del capitalismo.

Esa angustia es además siniestra porque apunta a la pregunta por el ser $\left(\right.$ dasein $\left.^{8}\right)$ en el sentido que le da Heidegger de "ser su ahî" a cada momento. El ser siempre está, solo permanece olvidado", cubierto por la fantasía que soporta la realidad diaria. Ahora, en esa repentina suspensión de Joi, la angustia retorna como algo familiar y conocido. Es en ese sentido en que la angustia, el ser y lo siniestro, están entrelazados. La suspensión de la representación, el congelado repentino de Joi en pleno acto amoroso, produce angustia porque le señala a ' $\mathrm{K}$ ' la miseria de su existencia como esclavo-replicante de la que intenta evadirse. La experiencia es siniestra porque el ser que permanecía oculto, velado en ese olvido al que se entrega el protagonista, retorna y emerge como sensación de angustia ${ }^{10}$ cuando la realidad pactada en connivencia con Joi (es decir con Wallace) se derrumba.

Joi es detenida por la realidad de 'K' (fig. 5), que es reclamado para aquello que fue programado. ' $\mathrm{K}$ ' por primera vez en el film intuye una herida, una duda angustiosa acerca de su existencia.

No es casual, entonces, que lo siniestro apunte a la fantasía amorosa y que Wallace se sirva de ella para ofrecer sus productos opiáceos. El amor es fantasía de plenitud, es reconocerse a través del otro, es darle sentido al ser en el mundo, justo lo opuesto a la angustia y, sin embargo, ambas sensaciones están separadas únicamente por una construcción, una fantasía que en el caso de $\mathrm{K}$ es dependiente de Wallace. El capitalismo es el demiurgo.

8 "El Dasein es el ente que soy cada vez yo mismo; su ser es siempre el mío" (Heidegger, 2003: 37). Heidegger utilizó el término Dasein, entendido como el «ser su ahí» de la existencia del sujeto que arrojado al mundo se abre a él. El Dasein alberga esa parte de sí que es el ser, que se siente tan próximo y cercano que se confunde con el yo-consciencia, pero que velado y alejado de su comprensión se le manifiesta como fenómeno mediante la angustia.

${ }^{9}$ Heidegger utiliza también el sentido ambiguo de la palabra alemana unheimlich que escoge Freud para hablar de lo siniestro porque el ser es para Heidegger aquello que el Dasein "siente como lo más cercano y sin embargo es lo más alejado de sí mismo" (2003: 207). De ahí que apuntemos a la posibilidad de que el fenómeno siniestro de Freud y la angustia de Heidegger señalen a modos fugaces de desvelamiento del ser cuya intensidad provoca una incertidumbre del sentido de la realidad en la que se desenvuelve.

10 "En lo referente a aquella estructura tan esencial llamada el fantasma. Verán ustedes que la estructura de la angustia no está lejos de ella, por la razón de que es ciertamente la misma" (Lacan, 2015: 11). 
Fig. 5. Fotograma de Blade Runner 2049 (Villeneuve, 2017). Blu-ray. Warner Bros. Entertainment Inc. (C)

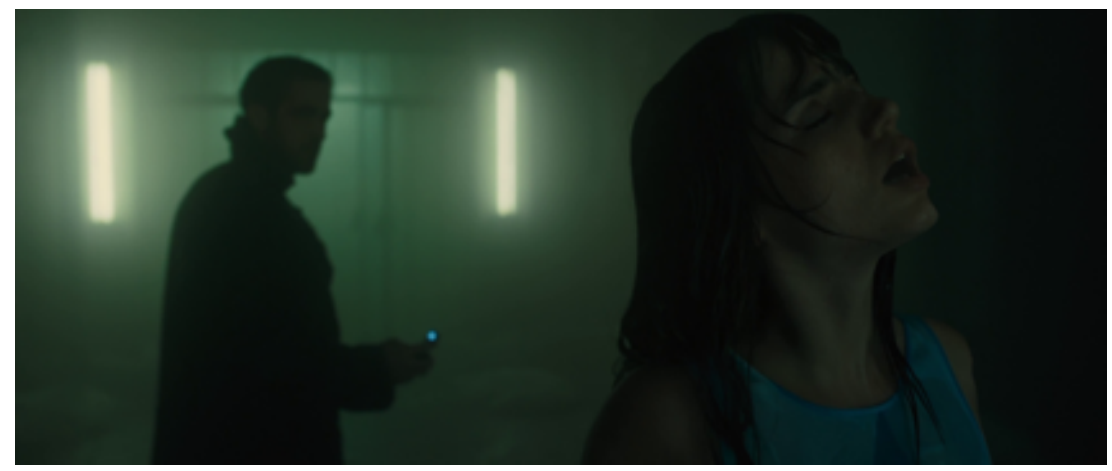

Sin embargo, pese a todo lo expuesto, lo siniestro no se manifiesta plenamente en esta secuencia de Blade Runner 2049. La aparición del mensaje de voz sutura con su causa el motivo de la suspensión de Joi, nos saca de esa extrañeza que hubiese podido comenzar a ser angustiante también para el espectador. La suspensión de los códigos de representación hegemónicos es tan breve, que cuando lo siniestro amenaza con manifestarse se reconduce el sentido narrativo a través de una causa, un motivo.

Por otra parte la lluvia tiene una carga particular en el díptico Blade Runner, la lluvia se funde con las lágrimas (fig. 6), tiene una profunda carga melancólica ${ }^{11}$, sentimiento también próximo a lo siniestro. La lluvia es aquella huella del tiempo que no cesa, la huella del ahora-soy a la que se aferraba el replicante Roy Batty. Una última ráfaga de singularidad, de reivindicación de la vida ante la muerte prefijada por el amo al esclavo, a su fecha de caducidad como producto.

Fig. 6. Fotograma de Blade Runner 2049 (Villeneuve, 2017). Blu-ray. Warner Bros. Entertainment Inc. (C)

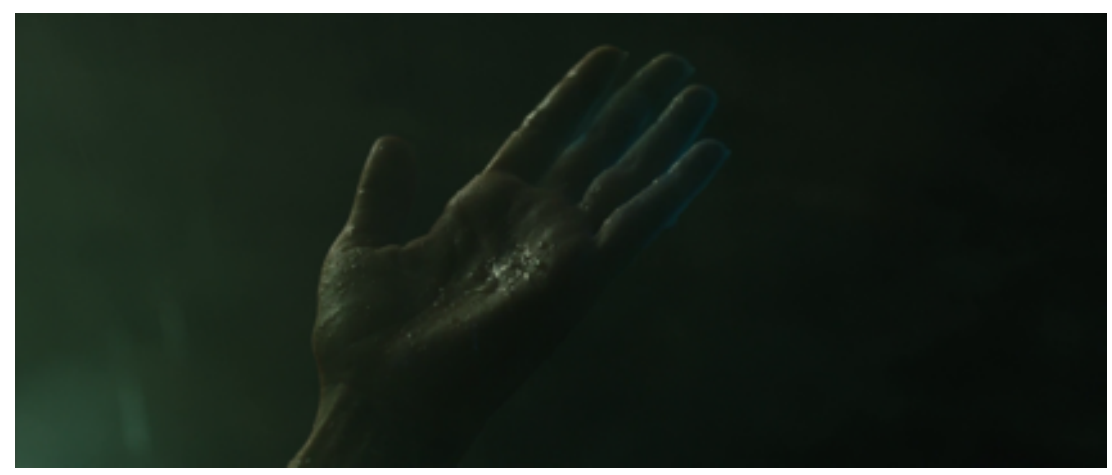

${ }^{11}$ Freud asocia la melancolía "a una pérdida de objeto sustraída de la conciencia" (Freud, 1992a: 243). 
¿Qué otra cosa es si no esa detención bajo la lluvia de una Joi sin cuerpo definido?, empapada, ojos cerrados, boca interrumpida. La consciencia se ve aquí atravesada no ya por lo real de la pasión, sino por la irrupción de un amo omnipresente (Wallace) que domina incluso la continuidad de la vida de sus esclavos ${ }^{12}$. Porque cada detención de la consciencia en la percepción del tiempo es, en cierto modo, una muerte. Por eso Joi quiere ser real, tener un cuerpo en el que pueda desaparecer de verdad.

Es a través del amor o de su algoritmo como Joi se libera, poco importa si ella cree que ama o ama sin creerlo, todo amor es representación, fantasía. Joi reclama primero un cuerpo, el de la prostituta, y después otro, el único posible, el del emanador, y lo reclama como acto propio. Reclama su individualidad para poder sacrificarla por el otro al que ama y que ' $\mathrm{K}$ ' pueda exponerse a perderla por medio de la muerte. Si eso no es amor, si Joi no está viva, entonces, como afirma Gaff, “¿Quién vive?”.

Así, no es casual que de la detención bajo la lluvia en pleno acto amoroso de esa evanescente Joi, pasemos por corte directo a la rotunda materialidad del osario de Rachel. A los restos de esa replicante que amó a Deckard, recogidos en un ataúd que es una caja expuesta a la mirada absoluta de la técnica, capaz de ver a través de la materia pero ciega como Wallace para elucidar lo humano. El amor de Rachel es el misterio y no su capacidad para engendrar hijos que persigue obsesivamente Wallace. Un milagro, afirmaba Scanner, un acto de fe, como el amor, que excede la técnica del dato y la neurociencia de Wallace, porque el amor se hace cargo del sujeto, lo expone, lo reivindica en su paso por el mundo. El amor y la muerte en Blade Runner 2049 son actos de liberación y resistencia, los únicos posibles en ese mundo distópico de explotación y sometimiento.

\section{De entre los muertos (I). Deckard y Rachel (2h 08' 55"- 2h 16'56")}

Las relaciones entre ' $\mathrm{K}$ ' y Joi encuentran su eco en las de Deckard y Rachel. Ambas, Joi y Rachel comparten su cualidad fantasmal. Esto se manifiesta en esa concatenación de secuencias en la que pasamos del plano de Joi congelada y translucida, al contundente contraste del esqueleto de Rachel, la materialidad de su muerte, los restos de lo que fue un cuerpo que amó. Todo lo que Joi no es todavía.

Más tarde, cuando Deckard asiste a la resurrección de Rachel que le oferta Wallace, Joi ya se ha asemejado a ella y ha adquirido algo específicamente humano; Joi ha sacrificado y reivindicado con su muerte el espacio único de su ser que le ha dado la capacidad de amar. Lo opuesto a la muerte no es la vida sino el amor, cuestión en la que Freud y antes que él los románticos ${ }^{13}$, incidieron. Lo mismo sucedía con los replicantes (Nexus 6) que se rebelaban,

${ }^{12}$ Nos basamos en la dialéctica entre amo y esclavo desarrollada por Alexandre Kojeve en su libro La dialéctica del amo y del esclavo en Hegel (1982), a partir de los conceptos expuestos por Hegel en La Fenomenología del espíritu (1966). La historia de la humanidad es la del sometimiento del hombre, en las que el esclavo trabaja para el amo ocioso, que recibe lo que este produce.

13 "El romanticismo [...] elabora en la práctica artística la experiencia de lo siniestro. Freud, por último, levanta el acta categorial de esta experiencia” (Trías, 2006: 144). 
algo de ese amor les atraviesa en su desconcierto ante la muerte; recordemos el beso de Roy ante el cadáver "retirado" de "Pris", su aullido.

Wallace trata de comprar a Deckard, cree que necesita encontrar a su hija para descifrar la clave que falta para lograr la autoreproducción de los replicantes, superar esa barrera que les separa de lo humano. Wallace apela primero al recuerdo, el sonido de las voces reverbera de forma particular en esta secuencia que tiene lugar en el refugio del creador, y lo hace sobre paredes en las que el agua se refleja esmerilante en el mismo tono atardecer de los espacios de Tyrrell, allí donde Deckard conoció a Rachel. Las cualidades del recinto son idóneas para avivar el recuerdo de Rachel, primero Wallace rescata un archivo e invoca el eco del espacio y del tiempo, el de las voces de Deckard y Rachel en el momento de conocerse.

Primero la voz, después la imagen. Tras esa rememoración sonora se produce un inserto aparentemente subjetivo del recuerdo de Deckard ante la primera visión de Rachel. Wallace le sugiere que quizás su enamoramiento fue parte de un plan, algo preconcebido y programado para lograr esa descendencia; “‘amor o precisión matemática?”, le pregunta Wallace. Para el creador ambos son lo mismo, el dato, la ciencia, puede crear el amor, pero Deckard le responde proclamando su subjetividad: "yo sé lo que es real". Wallace le afirma entonces que conoce su dolor, gracias a él sabe que es real lo que vivió porque proviene de la felicidad perdida que él le puede restituir ahora.

El espacio se oscurece y las palabras de Wallace que preceden a la aparición de Rachel, poseen una importante carga siniestra: "más felicidad, entonces". Se escuchan los tacones de Rachel que anuncian su presencia. El sonido es el otro gran incitador de lo siniestro muchas veces olvidado, el que anticipa, el que precede a un regreso de algo enterrado en la memoria. Tacones, pasos, que son el sonido dinámico de algo que se aproxima desde lejos, que recorre el espacio y tiempo que le separa de un reencuentro imposible, porque ese sonido regresa de la muerte. Es por eso que su silueta asciende de entre las profundidades (fig. 7). Rescatada la sombra después viene el gesto, el brazo en jarra, esos ademanes únicos del ser amado se reproducen y se aproximan hacia Deckard.

Fig. 7. Fotograma de Blade Runner 2049 (Villeneuve, 2017). Blu-ray. Warner Bros. Entertainment Inc. (C)

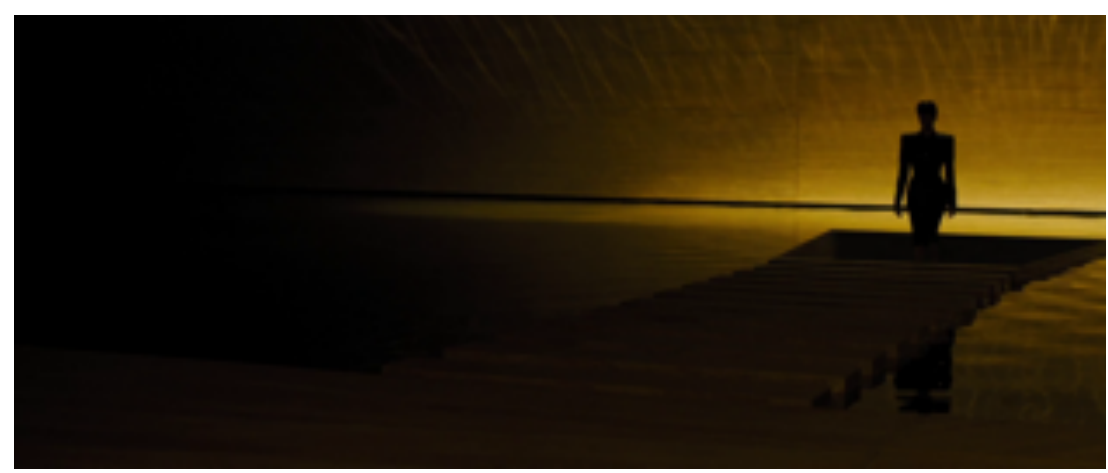




\section{MHCJ Vol. 12 (1) | Año 2021 - Artículo nº 9 (176) - Páginas 181 a 202 - mhjournal.org}

Wallace cree seducir a Deckard ofreciéndole una réplica que le devuelva el goce y aparte el dolor, de forma similar a lo que su empresa hace con la virtual Joi. Wallace es incapaz de apreciar la diferencia, para él Rachel es recuperable replicando la información y algoritmos de su conciencia, todo se reduce a lo que la avanzada técnica reproduce.

La resucitada alcanza a Deckard, le pregunta si la ha echado de menos. Deckard la rechaza. Lo inquietante es que esa copia de Rachel parece albergar sus recuerdos, ella cree ser Rachel. Para Wallace no hay diferencia pero hay una fundamental, un error en la réplica: "sus ojos eran verdes", zanja Deckard.

Evidentemente se trata de mucho más que del color de sus ojos, los de la Rachel original no eran verdes. Lo que está echándole en cara Deckard a un creador ciego para ver lo particular, lo humano, no es un error técnico, sino su incapacidad para comprender lo que supone la mirada. La mirada conlleva una subjetividad, una forma única de aprehender el mundo. Rachel alcanzó para Deckard un lugar irremplazable cuando esta se constituyó como sujeto, se humanizó, a partir de ese reconocimiento que da el amor, auténtico generador de imágenes-memoria. Porque Rachel, recordemos, no tenía recuerdos sino implantes ${ }^{14}$.

La mirada vampiriza la imagen por el ser en el tiempo que la hace suya, imagen que será recuerdo espumeante e intransferible, ancla, pérdida y reencuentro rizomático (lugar para perderse y reencontrarse). Ahí está una de las claves de lo humano, a su vez límite de la ciencia. Es contra este concepto de lo subjetivo y evanescente de las imágenes ante el que el dios de la técnica Wallace se topa una y otra vez, impotente e incapaz de comprender que lo humano excede lo datable y objetivo.

La identificación de los replicantes en las dos Blade Runner está en el ojo, pero la identidad juega en el Edén de la mirada (fig. 8). Wallace está ciego para ver ese abismo vital que va de las imágenes del ojo-aparato receptor al sujeto que las hace arder, ciego para comprender la relación entre el amor y las imágenes cuando tocan lo real en los ojos del otro que nos devuelve la mirada.

${ }^{14}$ Recordemos que en Blade Runner Rachel se ampara en las imágenes-recuerdo, las fotografías, para afirmar las raíces de su identidad humana, pero estas resultaron ser falsas. En el futuro será su hija, la que le cuesta la vida, la sensible creadora de esas imágenes-recuerdo que le permiten, gracias a ' $\mathrm{K}$ ' reencontrarse con su padre. 


\section{MHCJ Vol. 12 (1) | Año 2021 - Artículo nº 9 (176) - Páginas 181 a 202 - mhjournal.org}

Fig. 8. Fotograma de Blade Runner (Scott, 1982). Blu-ray. Warner Bros. Entertainment Inc. C)

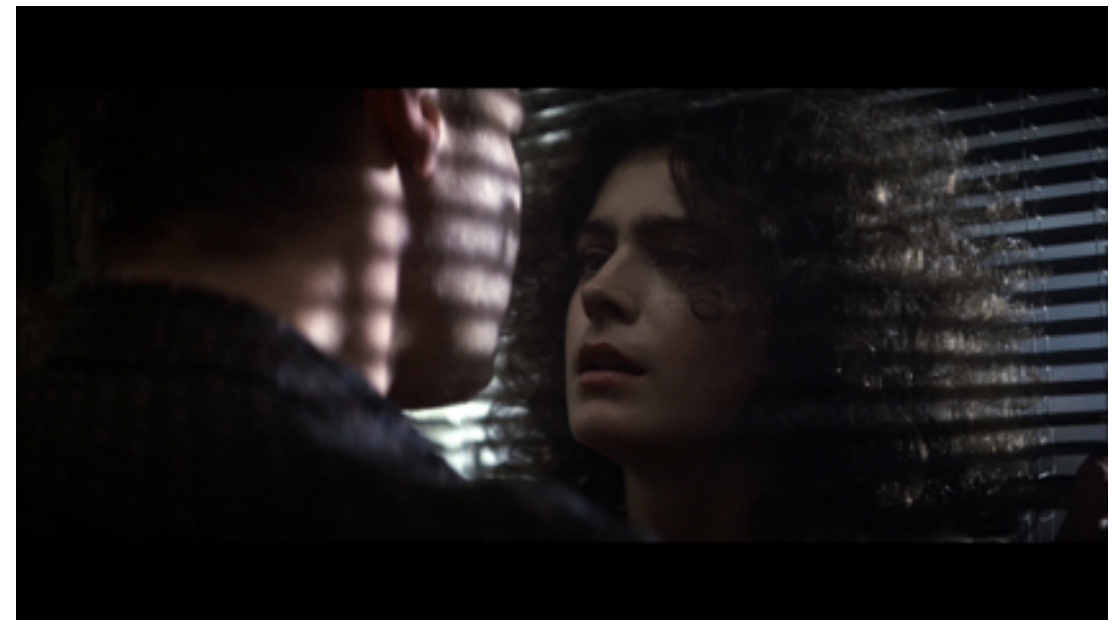

Además está la palabra (Blade Runner: 1h 11'40”)

Deckard— "Bésame..."

Rachel_ "No me fío de mi memoria"

Deckard— "Di bésame"

Rachel_..."Bésame"

Deckard—“Te deseo"

Rachel— "Te deseo"

"Di te deseo" le obligó a decir Deckard a Rachel en Blade Runner.

El deseo como herida de lo humano que se vertebra a través de la palabra ${ }^{15}$ hace a Rachel capaz de ser y amar al otro, también de sufrir y morir, eso es todo lo que puede portar consigo una mirada. Eso es justo lo real que Wallace no puede captar. Es por eso que Rachel está para siempre excluida de su producción seriada. No se puede replicar lo que se supo único. El gesto de amor post-mortem de Deckard es no renunciar al dolor para mantener viva consigo a Rachel.

Los temas de lo siniestro en esta secuencia del retorno de Rachel están presentes: la repetición, porque todo retorno es repetición y Rachel vuelve de entre los muertos replicando sus gestos, reclamando el amor de Deckard. El doble, en esa figura que afirma ser Rachel, autómata perfecta de la que se puede dudar su estatus viviente. Incluso la amputación de los ojos aparece en esa calavera que porta Wallace, probablemente de la auténtica Rachel, y la referencia a ese error en el color de los ojos de la sustituta que echa en cara Deckard a

15 "Desde luego, el signo no puede aprehender lo real. Pero la palabra puede localizarlo, ceñirlo y desafiarlo" (González Requena, 2010: 25). 
su padre-creador ciego. El tratamiento además induce al misterio, se demora la aparición de Rachel, precedida por el sonido de su presencia, se oscurece el espacio.

Hay inquietud siniestra en el regreso de Rachel, sus ejes temáticos están ahí, pero el fenómeno no hace acto de presencia en toda su rotundidad. El motivo, los temas siniestros, ese retorno de lo familiar que ahora se vuelve extraño que es Rachel, no viene acompañado de una suspensión ni quiebra narrativa que haga evidentes los códigos de la representación hegemónica que le sirven de asidero al espectador.

Fig. 9. Fotograma de Blade Runner 2049 (Villeneuve, 2017). Blu-ray. Warner Bros. Entertainment Inc. (C)

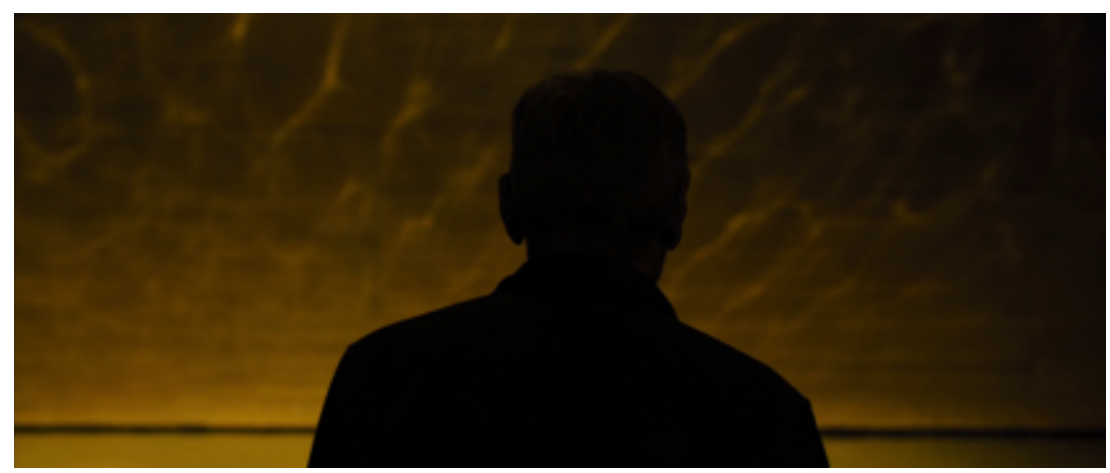

\subsection{De entre los muertos (II). El regreso de Joi (2h 16' 56"- 2h 18' 39")}

La espalda de Deckard precede a la de ' $\mathrm{K}$ ' que abre esta secuencia (figuras 9 y 10), son planos medios en los que ambos se presentan recogidos en el dolor y recuerdo de sus pérdidas (Rachel y Joi).

No es casual que lo siniestro asome entre el amor y la muerte y que a su vez todo ello esté ligado a la identidad y la pérdida mediadas por la angustia ${ }^{16}$. El acierto de Blade Runner 2049 consiste deslizar lo siniestro a través de la representación de la realidad que pone en juego el imaginario del capitalismo. Tras él no hay nada, solo vacío, el vértigo de lo siniestro y su angustia, pero una angustia que, como vamos a ver en ' $\mathrm{K}$ ', es necesaria para retomar el sentido del ser en el mundo. Una angustia como particularidad de lo siniestro que engarza así con la intuición del ser de Heidegger.

' $\mathrm{K}$ ' camina envuelto en pesadumbre, acaba de perder a Joi cuando su gigantesca imagen publicitaria le reclama con las mismas palabras que una vez le dedicó al llegar a casa: "menudo día, ¿verdad?". La lluvia también remite a ella y juega como memento melodramático, evocando el momento que compartieron, pero fue también bajo esa lluvia

16 "Cuando al sujeto le falta la ausencia, el vacío posible que hace habitable un espacio, entonces aparece la angustia” (Bassols, 2011: 66). 


\section{MHCJ Vol. 12 (1) | Año 2021 - Artículo nº 9 (176) - Páginas 181 a 202 - mhjournal.org}

donde ' $\mathrm{K}$ ' intuyó la representación de la que Joi formaba parte.

Fig. 10. Fotograma de Blade Runner 2049 (Villeneuve, 2017). Blu-ray. Warner Bros. Entertainment Inc. (C)

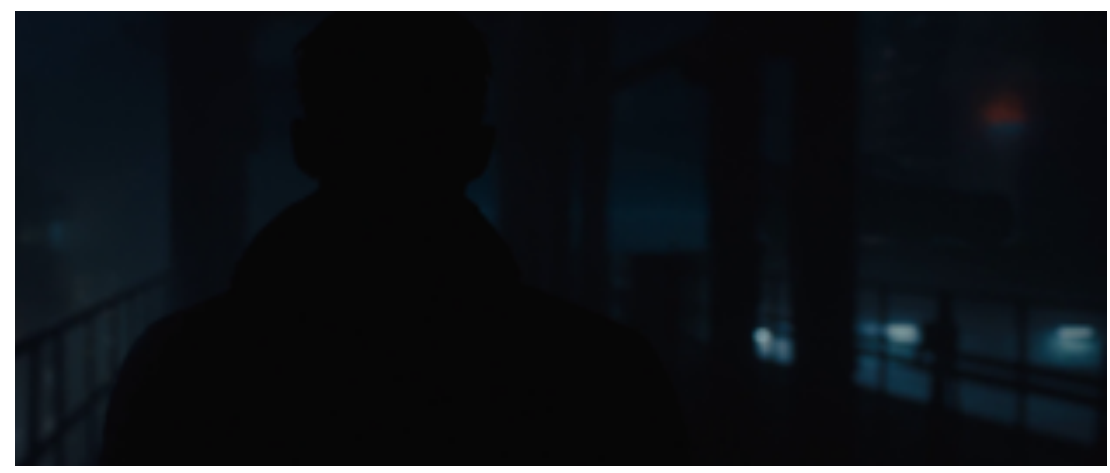

Esa Joi gigante se dirige a él seductoramente, ofrece su cuerpo desnudo y vuelve a enmarcarse en su espacio publicitario, el mismo que ha rebasado con creces para ofrecerse y ser invasiva. Joi es "todo lo que quieres". El objeto promete en su consumo la falacia de la plena satisfacción.

Lo siniestro en esta secuencia participa de los mismos temas que en el regreso de Rachel. $\mathrm{Si}$ bien la demora y suspense en la aparición de Rachel no tiene nada que ver con la invasiva aparición del producto Joi (fig. 11), sí existe el mismo tratamiento del sonido que matiza de irrealidad a una imagen amada que retorna de repente. Vuelve aquí a deslizarse el tema de la amputación de los ojos, que aparecen en Joi completamente negros, sin pupilas, pero la figura autómata, esa muñeca enorme y genérica, no le reconoce, al contrario que la Rachel "retornada" de memoria implantada con Deckard.

Fig. 11. Fotograma de Blade Runner 2049 (Villeneuve, 2017). Blu-ray. Warner Bros. Entertainment Inc. (C)

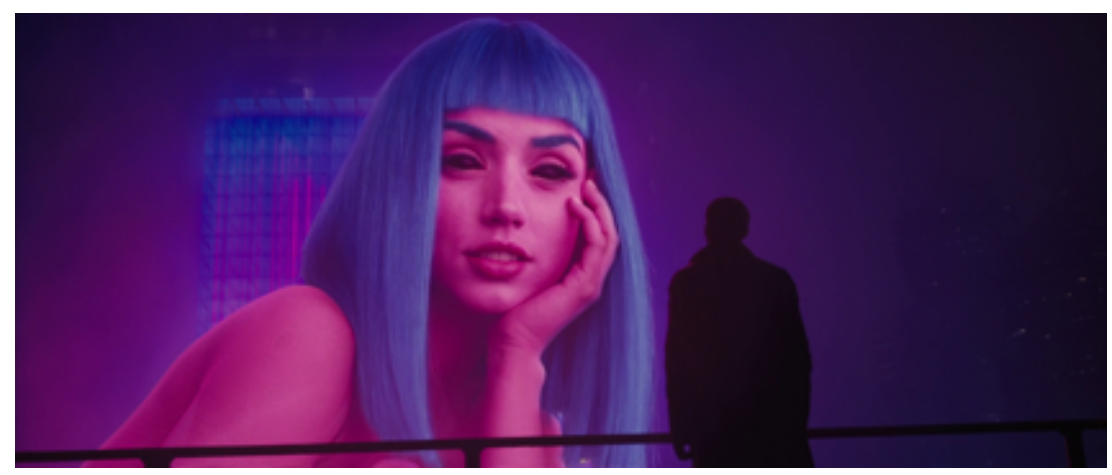


Hemos señalado en la secuencia anterior las implicaciones del ojo y la mirada en Blade Runner 2049, aquí el hecho de que Joi aparezca con esas manchas negras allá donde deberían estar las pupilas es sintomático; por un lado realza su carácter siniestro, lo que se le ha amputado aquí a Joi con esa ausencia de pupilas es su individualidad y uno de los rasgos más apreciados en el ser amado, no ya sus ojos, sino su mirada. Resuena aquí de nuevo la frase de Deckard: "Sus ojos eran verdes". Una Joi programable, el producto que promete darte todo lo que quieres, solo puede estar vacío, como esas lagunas negras que miran ya sin ver a ' $\mathrm{K}$ '.

"He estado dentro de ti y no hay gran cosa" le dijo la prostituta Mariette a Joi. Mariette es una de las replicantes rebeldes, por ello parece conocer mejor el vacío que esconden las imágenes de consumo ${ }^{17}$. Eso es lo que ' $\mathrm{K}$ ' comprende ahora ante esa imagen de Joi.

Rachel retorna con un cuerpo, una memoria replicada de un tiempo compartido con Deckard, pero ha perdido lo real ${ }^{18}$ en su mirada, no es ella siendo ella. En Joi ocurre lo mismo pero el capitalismo digital, perfecto compuesto para el carácter líquido de sus ofertas, ya no necesita esconder el producto, es la misma lógica que Wallace aplica a Deckard, solo que aquí le pide al consumidor su modelaje. Esa Joi no tiene mirada como tampoco la nueva Rachel. Las dos comparten la réplica perfecta de sus referentes, pero lo que ambas no pueden ser es lo que aquellas sí fueron, sujetos que se constituyeron por medio del dolor, entre el amor y la muerte de su paso por el mundo a través de la mirada. Nadie retorna de donde no se vuelve, para eso ya están la ausencia y la memoria.

Ante esa Joi estandarizada, prostituida y volátil que le apela sin reconocerle, K siente el dolor y angustia. No hay más que ver su rostro para comprender que la verdad duele, pero a través de la angustia ${ }^{19}$ toma conciencia de la realidad de su existencia hasta rebelarse precisamente contra el amo-creador de esa Joi. Esta es la razón de ser de esta secuencia que disuelve hacia su final el deslizamiento siniestro que había provocado la aparición de la nueva Joi al darle un motivo preciso, el paso a la rebelión de K, remarcado por el leitmotiv y la innecesaria voz en off introspectiva.

${ }^{17}$ Recordemos que las colonias exteriores (off-world) son ese paraíso prometido, las zonas residenciales que se publicitan en los zepelínes de Blade Runner. Los Nexus 6, que han trabajado en ellas, miran esa publicidad con desprecio, saben que solo hay explotación en esas colonias. Tampoco es casual que Wallace cuando no pueda convencer a Deckard le amenace precisamente con conocer el dolor en esas colonias. En el reverso de la publicidad está la verdad.

${ }^{18}$ Lo real sería aquí esa parte del sujeto (Rachel) que la constituyó como única ante ella misma y a los ojos de Deckard. Su complicidad forma parte de lo real, el resto que falta de Rachel, esa parte de ella que no se aviene a ser reintegrada en la realidad simbólica que teje el discurso tecnológico y que toma forma con su réplica. En coherencia, es por medio de la mirada entre ambos donde Deckard siente la ausencia del ser amado. Lo real (de Rachel para Deckard) escapa a toda ciencia, código o paradigma.

${ }^{19} \mathrm{La}$ angustia designa un agujero en lo real y permite que ese agujero se mantenga (Recalde, 2014: 40). 


\section{Conclusiones: lo siniestro en Blade Runner 2049}

Emprendimos el artículo con el objetivo de dilucidar si realmente lo siniestro hace acto de presencia en Blade Runner 2049. Sin embargo, partimos de unas premisas básicas que afectan precisamente a la consideración de lo siniestro fílmico; así, para que lo siniestro pueda manifestarse en toda su radicalidad, colocamos en posición privilegiada a la incertidumbre frente al resto de temas siniestros. Fundamentamos que lo siniestro debe darse en la forma fílmica a partir de la suspensión de los códigos del M.R.I ${ }^{20}$. En caso contrario los temas siniestros apuntarán al fenómeno, pero este no hará acto de presencia.

En las dos Blade Runner el amor constituye al sujeto, le confiere estatuto humano. Blade Runner 2049 propone además una lectura muy sugerente al relacionar la emergencia de lo siniestro con el amor. En ese engarce entre el amor perdido, pura vivencia intransmisible y subjetiva del ser, con el ofrecimiento objetivado de su imagen como producto de consumo (Rachel y Joi ‘retornadas`) es por donde Blade Runner 2049 tiene el acierto de valerse de los temas siniestros para señalar la mentira capitalista a través de sus imágenes vacías. Lo siniestro es pues una verdad que se manifiesta como sensación, una falta ante el olvido de lo humano, el fenómeno que en Blade Runner 2049 desvela la miseria que trata de ocultar la interpretación de la realidad capitalista, que se ha impuesto de forma absoluta.

La incertidumbre sacude entonces a los protagonistas que la experimentan como angustia. En Blade Runner 2049, y esta es nuestra conclusión, esa angustia se presenta con la apariencia de los temas siniestros freudianos, pero deriva en una angustia precursora, en el sentido heideggeriano de reivindicación de la existencia de Deckard y K, que les llevará a enfrentarse a Wallace.

Concluimos que lo siniestro en toda su radicalidad no tiene lugar en la película porque no alcanza a la representación. Sus temas aparecen pero no están acompañados de una incertidumbre interpretativa que afecte a la forma fílmica. Esto es, de una ruptura o suspensión de los códigos convencionales del M.R.I que sirven para crear certidumbre en el espectador. En el análisis de las secuencias ya advertimos cómo el congelado de Joi bajo la lluvia y el tratamiento sonoro aproxima a Blade Runner 2049 a lo siniestro, pero no se llega a generar una fisura en el relato a partir de la cual supure el fenómeno. La suspensión de Joi es reintegrada en la diégesis mediante una causa que aparece demasiado pronto suturando el sentido. Si la incertidumbre no tiene lugar, lo siniestro no puede emerger en toda su radicalidad. Así acontece a nuestro entender en Blade Runner 2049.

\section{Bibliografía}

Alemán, J. y Larriera, S. (1998). Lacan: Heidegger. Elpsicoanálisis en la tarea del pensar. Málaga: Miguel Gómez Ediciones.

${ }^{20}$ El M.R.I. busca la certeza sin resto para el espectador: «que lo que se le ofrece a la mirada es todo. No solo todo lo que hay sino que lo que hay es todo, que no queda resto tras su mirada» (Palao, 2004: 239). 


\section{MHCJ Vol. 12 (1) | Año 2021 - Artículo no 9 (176) - Páginas 181 a 202 - mhjournal.org}

Bassols, M. (2011). El caballo del pensamiento. Granada: Editorial Universidad de Granada.

Bauman, Z. (2000). Modernidad líquida. Buenos Aires: Fondo de Cultura Económica (FCE).

--(2005): Amor líquido. Acerca de la fragilidad de los vínculos humanos. Buenos Aires: Fondo de Cultura Económica (FCE).

--(2013): Vida líquida. Barcelona: Austral.

Burch, N. (1985). Itinerarios. La educación de un soñador del Cine. Bilbao: Caja de Ahorros Vizcaína.

Freud, S. (1992a). Duelo y Melancolía. Obras completas, XIV, Buenos Aires: Amorrortu Ediciones.

--(1992b): Lo Siniestro. Obras completas, XVII, Buenos Aires: Amorrortu Ediciones.

Fukuyama, F. (1992). El fin de la bistoria y el último hombre. Barcelona: Planeta.

Gómez Tarín, F. J. (2006). Guía para very Analizar: Al final de la escapada. Jean-Luc Godard, 1959. Valencia, Barcelona: Nau Llibres, Octaedro.

--(2007): The Curse of the Cat People: presencia de lo siniestro (Val Lewton como exponente). Revista Latina de Comunicación Social, núm. 33, La Laguna, septiembre. Recuperado de http://apolo.uji.es/fjgt/Curse.PDF

González Requena, J. (2010). Lo Real. Trama y Fondo, Número 29, Segovia: Asociación Cultural Trama y Fondo. Recuperado de http://www.tramayfondo.com/revista/ libros/142/01_Requena.pdf

Hegel, G.W.F. (1966): La fenomenología del espiritu. México: Fondo de Cultura Económica (FCE).

Heidegger, M. (2003). Ser y tiempo. Madrid: Trotta.

Hoffmann, E.T.A (2016). El hombre de arena. Nocturnos. Madrid: Alianza Editorial

Kojeve, A. (1982). La dialéctica del amo y del esclavo en Hegel. Buenos Aires: La Pléyade.

Lacan J. (2015). El seminario. Libro 10, La angustia, Buenos Aires: Paidós.

Palao, J. A.(2004). La profecía de la imagen-mundo: por una genealogía del paradigma informativo. Valencia: Ediciones de la Filmoteca.

Recalde, M. (2014). Angustia. Un real para el siglo XXI. Volumen del IX Congreso de la Asociación Mundial de Psicoanálisis, Buenos Aires: Grama Ediciones.

Stam, Robert (2001). Teorías del cine. Barcelona: Paidós.

Trías, E. (2006). Lo bello y lo siniestro. Barcelona: Debolsillo. 
Žižek, S. (1994). Todo lo que siempre quiso saber sobre Lacan y nunca se atrevió a preguntarle a Hitchcock, Žižek, S. (Comp.). Buenos Aires: Manantial.

\section{Uso de imágenes}

Las imágenes utilizadas como figuras en este artículo son elementos centrales del análisis, realizado únicamente con fines científicos en el ámbito académico.

\section{Bibliografía}

Deeley, M. (productor) y Ridley, S. (director) (1982). Blade Runner [cinta cinematográfica]. EE.UU.: Warner Brothers.

Franco L. (productor) y Carpenter, J. (director) (1988). They Live [cinta cinematográfica]. EE.UU.: Universal Pictures.

Hitchcock, A. (productor) y Hitchcock, A. (director) (1958). Vertigo [cinta cinematográfica]. EE.UU.: Paramount Pictures.

Johnson, B., Kosove, A. A., Sikes, C., Yorkin, B. (productores) y Villeneuve, J. (director) (2017). Blade Runner 2049 [cinta cinematográfica]. EE.UU.: Warner Brothers.

Rosebaum, M., Misch, G., Wieser, R., Fiennes, S. (productores) y Fiennes, S. (directora) (2012). The Pervert's Guide to Ideology [documental].Reino Unido, Irlanda.: Lone Star, Mischief Films, Amoeba Film production. 
MHCJ Vol. 12 (1) | Año 2021 - Artículo n 9 (176) - Páginas 181 a 202 - mhjournal.org

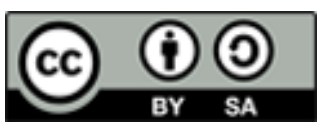

Licencia Creative Commons

Miguel Hernández Communication Journal

mhjournal.org

\section{Cómo citar este texto:}

Marcos Joaquin Ferrer (2021): Del amor a lo siniestro en Blade Runner 2049, en Miguel Hernández Communication Journal, Vol. 12 (1), pp. 181 a 202. Universidad Miguel Hernández, UMH (Elche-Alicante). DOI: https://doi.org/10.21134/mhcj.v12i.944 